\title{
Novel Hyaluronic Acid-Chitosan Nanoparticles for Ocular Gene Therapy
}

\author{
Maria de la Fuente, Begoña Seijo, and Maria J. Alonso
}

Purpose. Gene therapy offers a promising alternative for the treatment of ocular diseases. However, the implementation of this type of therapy is actually hampered by the lack of an efficient ocular gene delivery carrier. The main objective of the present work was to assess the effectiveness and investigate the mechanism of action of a new type of nanoparticle made of two bioadhesive polysaccharides, hyaluronic acid (HA) and chitosan (CS), intended for the delivery of genes to the cornea and conjunctiva.

Methods. The nanoparticles were obtained by a very mild ionotropic gelation technique. They were loaded with either the model plasmid pEGFP or $\mathrm{p} \beta$-gal. Transfection and toxicological studies were conducted in human corneal epithelial (HCE) and normal human conjunctival (IOBA-NHC) cell lines. The mechanism of internalization of the nanoparticles by the corneal and conjunctival cells was investigated by using fluorescence confocal microscopy.

RESULTs. The nanoparticles had a size in the range of 100 to 235 $\mathrm{nm}$ and a $\zeta$-potential of -30 to $+28 \mathrm{mV}$. The results of the transfection studies showed that HA-CS nanoparticles were able to provide high transfection levels (up to $15 \%$ of cells transfected), without affecting cell viability. The confocal images indicated that HA-CS nanoparticles were internalized by fluid endocytosis and that this endocytic process was mediated by the hyaluronan receptor $\mathrm{CD} 44$.

Conclusions. The results give evidence of the potential of HA-CS nanoparticles for the targeting and further transfer of genes to the ocular surface. (Invest Ophthalmol Vis Sci. 2008; 49:2016-2024) DOI:10.1167/iovs.07-1077

G ene delivery holds special promise for the treatment of ocular diseases. ${ }^{1}$ As with any other modality of administration, a major challenge in ocular gene therapy has become the effective delivery of genetic material to the nucleus of the target cell. ${ }^{2,3}$ In recent years, nonviral vectors and especially those resulting from the use of nanotechnologies have received

From the Department of Pharmacy and Pharmaceutical Technology, Faculty of Pharmacy, University of Santiago de Compostela, Santiago de Compostela, Spain.

Supported by Xunta de Galicia Grant PGIDIT03BTF20301PR; Spanish Ministry of Education and Sciences (MEC) Grant (MAT 200404792-C02-02); and a grant from the Spanish Government (MD). The antibody Hermes-1 developed by Eugene Butchner was obtained from the Developmental Studies Hybridoma Bank developed under the auspices of the NIHC and maintained by the Department of Biological Sciences University of Iowa, Iowa City.

Submitted for publication August 16, 2007; revised December 14, 2007; accepted March 3, 2008.

Disclosure: M. de la Fuente, Advancell (P); B. Seijo, Advancell (P); M.J. Alonso, Advancell (C, P)

The publication costs of this article were defrayed in part by page charge payment. This article must therefore be marked "advertisement" in accordance with 18 U.S.C. $\$ 1734$ solely to indicate this fact.

Corresponding author: Maria J. Alonso, Department of Pharmacy and Pharmaceutical Technology, University of Santiago de Compostela, Faculty of Pharmacy, Campus Sur, 15782 Santiago de Compostela, Spain; ffmjalon@usc.es. increasing attention for achieving the delivery of genetic material to the eye. ${ }^{4-7}$ The selection of the route of administration depends primarily on the target tissue, being traditionally the topical and the subconjunctival used for anterior targets. ${ }^{8}$ However, presumably due to tear flow, blinking and low penetration of the vector through epithelial tight junctions, the challenge of achieving effective topical gene transfer has led to the prevalence of invasive administration to the anterior chamber and corneal stroma. ${ }^{9}$ As a consequence, for the instillation of genes over the ocular surface, the development of a suitable delivery system becomes a requisite for achieving effective concentrations at the intended site over a sufficient period after administration. One of the most promising current approaches relies on the use of mucoadhesive nanoparticles that interact with the ocular mucosa, thus increasing the contact time on the eye surface. ${ }^{10,11}$

With this premise in mind, we developed nanoparticles consisting of two bioadhesive and biocompatible polysaccharides, hyaluronic acid (HA) and chitosan (CS), intended for the delivery of complex macromolecules to the ocular surface.

The original idea of incorporating HA into the nanoparticles was conceived to improve their cellular targeting capacity. Indeed, apart from its biocompatibility, biodegradability, and mucoadhesive character, HA is known for its implication in several processes, such as the regeneration of corneal and conjunctival epithelial cells, through an interaction with the CD 44 receptor. ${ }^{12}$ CD 44 is expressed in the human cornea and conjunctiva ${ }^{13,14}$ and participates in a wide variety of cellular functions, including receptor-mediated internalization and degradation of hyaluronan. ${ }^{15,16}$ For example, this receptor-mediated process has been reported to be the mechanistic explanation for the cellular uptake of HA-targeted liposomes to tumor cells that overexpress the CD44 receptor. ${ }^{17}$

On the other hand, our group has found that both CS nanoparticles and liposome-CS nanoparticle complexes interact with and penetrate the corneal and conjunctival epithelia. ${ }^{18-20}$ Moreover, CS is a biocompatible polysaccharide that has been extensively used for cell transfection. ${ }^{21-23}$

Hence, our goal in the present work was to evaluate the potential of a new gene nanocarrier, consisting of HA and CS, specially designed for the specific targeting and intracellular delivery of genes into the ocular epithelial cells. With this idea in mind, we prepared different nanoparticulate compositions, with regard for the polysaccharides molecular weight and HA-CS mass ratios, and studied their cytotoxicity, transfection efficiency, and cell uptake in two cell models: human corneal epithelial (HCE) and normal human conjunctival (IOBA-NHC) cells. Finally, the capacity of the nanoparticles to interact with the CD44 receptor was explored, as well as the role of this interaction in gene transfer.

\section{Materials ANd Methods}

\section{Chemicals}

Sodium hyaluronate ophthalmic grade (having a molecular mass of $\sim 170 \mathrm{kDa}$ ) was a gift from Bioibérica (Barcelona, Spain). Ultrapure chitosan hydrochloride salt (Protasan UP CL 113, having a molecular mass of $\sim 110 \mathrm{kDa}$ ) was purchased from Pronova Biomedical A.S. 
(Oslo, Norway). Plasmid DNA (pDNA) encoding green fluorescent protein (pEGFP-C1) and pDNA encoding $\beta$-galactosidase ( $\beta \beta$-gal) driven by a CMV promoter, were purchased from Elim Biopharmaceuticals (Hayward, CA). Pentasodium tripolyphosphate (TPP), acetaldehyde, ONPG (2-Nitrophenyl $\beta$-D-galactopyranoside), and $\beta$-galactosidase, were all obtained from Sigma-Aldrich (Madrid, Spain). Fluoresceinamine and cyclohexyl isocyanide were purchased from Fluka (Madrid, Spain). A 1-kbp DNA ladder was obtained from Invitrogen-Life Technologies (Barcelona, Spain). All other solvents and chemicals were of the highest commercial grade available.

\section{Depolymerization of CS and HA}

Chitosan oligomers (CSO) were obtained from Protasan UP CL 113 (Novamatrix, Sandvika, Norway) by sodium nitrite degradation, as previously described by Janes and Alonso. ${ }^{24}$ Briefly, $200 \mu \mathrm{L}$ of $0.1 \mathrm{M}$ $\mathrm{NaNO}_{2}$ was added to $4 \mathrm{~mL}$ of a CS solution of $10 \mathrm{mg} / \mathrm{mL}$. The reaction was left overnight, to ensure completion of the degradation, and oligomers with 10 - to $12-\mathrm{kDa}$ molecular mass were recovered by freeze-drying. The molecular size of the CSO was verified by sizeexclusion chromatography-multiangle laser-light scattering (SECMALLS). An isocratic pump (G1310A Iso Pump; Hewlett Packard, Palo Alto, CA) was connected to analytic PSS GPC columns (10 $\mu \mathrm{m}, 30 \AA$, $8 \times 50 \mathrm{~mm}$, NOA0830103E1; and $10 \mu \mathrm{m}, 3000 \AA, 8 \times 300 \mathrm{~mm}$, NOA0830103E3; Novema, Wroclaw Poland). An SEC-MALLS system (PSS SLD7000 MALLS detector; Brookhaven Instruments Corp., Holtsville, NY) operating at $660 \mathrm{~nm}$ and a refractive index detector (model G1362A; Agilent, Palo Alto, CA) were connected online. A buffer containing $0.15 \mathrm{M} \mathrm{NH}_{4} \mathrm{OAc}$ and $0.2 \mathrm{M} \mathrm{AcOH}(\mathrm{pH} 4.5)$ was used as the eluent. Polymer solutions were filtered through $0.2-\mu \mathrm{m}$ pore size membranes (VWR International, Ltd., Lutterworth, UK) before injection. Polymer concentration was in the range of 0.30 to $0.16 \mathrm{mg} / \mathrm{mL}$. The refractive index increment $\mathrm{dn} / \mathrm{dC}$ was set at 0.188 .

For the enzymatic degradation of HA, $52.7 \mathrm{mg} \mathrm{HA}$ was dissolved in $20 \mathrm{~mL}$ of buffer ( $0.1 \mathrm{M}$ sodium acetate, $0.1 \mathrm{M}$ sodium chloride, $\mathrm{pH} 7.2$ ) under magnetic stirring. After HA was completely dissolved, $5 \mathrm{mg}$ hyaluronidase (from bovine testes, activity 1000 units/mg, Sigma-Aldrich, St. Louis, MO) was added to the solution, which was then kept for 24 hours in a shaking incubator at $37^{\circ} \mathrm{C}$. After the enzymatic splitting reaction the mixture was centrifuged (3500 g, 30 minutes) in filters (Amicon Ultra, MWCO $10 \mathrm{kDa}$; Millipore Corp., Billerica, MA), and the filtrated HA oligomers (HAO) of interest (MW $<10 \mathrm{kDa}$ ) were recovered by freeze drying.

\section{Nanoparticle Preparation}

Nanoparticles (NPs) were spontaneously obtained by ionotropic gelification, according to the methodology previously developed by our group albeit with minor modifications. ${ }^{25,26}$ The hyaluronan solution (HA or HAO), mixed with the cross-linker TPP, was added over the chitosan solution (CS or CSO) under magnetic stirring. Agitation was maintained for 10 minutes, to allow the complete formation of the system. The CS or CSO solution was prepared at a concentration of $0.625 \mathrm{mg} / \mathrm{mL}$, and the volume used was fixed at $0.750 \mathrm{~mL}$. Alternatively $50 \mu \mathrm{L}$ of a TPP solution $(0.5 \mathrm{mg} / \mathrm{mL})$ were mixed with the HA or HAO solution before the formation of the NPs. To modulate the weight ratio of the polysaccharides that constituted the NPs (HA:CS 1:2, 1:1, or $2: 1$ ), we modulated the concentration and volumes of the hyaluronan solution $(0.625$ or $1.25 \mathrm{mg} / \mathrm{mL}$ and 0.375 or $0.750 \mathrm{~mL}$, respective1y).The NPs were loaded with pEGFP, or $\mathrm{p} \beta$-gal, by incorporating the required amount of the model plasmid in the HA/TPP phase. The theoretical loading was fixed at $7 \%$ (wt/wt).

NPs composed solely of CS were also prepared by ionic gelification. In such a case, $0.2 \mathrm{~mL}$ of TPP at a concentration of $0.625 \mathrm{mg} / \mathrm{mL}$ were added over $1 \mathrm{~mL}$ of CS ( $1 \mathrm{mg} / \mathrm{mL})$. In the preparation of NPs made only from CSO, $0.2 \mathrm{~mL}$ of TPP at a concentration or $0.42 \mathrm{mg} / \mathrm{mL}$ were added over $1 \mathrm{~mL}$ of CSO solution $(1 \mathrm{mg} / \mathrm{mL})$. NPs were loaded by including pEGFP in the TPP solution ( $7 \% \mathrm{wt} / \mathrm{wt})$.

\section{Nanoparticle Characterization}

The mean particle size and the size distribution of the NPs were determined by photon correlation spectroscopy (PCS). The $\zeta$-potential values of the NPs were obtained by laser Doppler anemometry (LDA), measuring the mean electrophoretic mobility. The PCS and LDA analysis were performed (Zetasizer 3000 HS; Malvern Instruments, Malvern, UK).

The association of pDNA with the NP was observed by a conventional agarose gel electrophoresis assay. Samples of the NPs were placed in $1 \%$ agarose gel containing ethidium bromide and were run for 90 minutes at $60 \mathrm{~V}$ (Sub-Cell GT 96/192; Bio-Rad Laboratories Ltd., Herts, UK) in TAE buffer (Tris-acetate-EDTA; pH 8).

\section{Cell Cultures: HCE and IOBA-NHC Cells}

Mycoplasma-free immortalized HCE cells were a gift from Arto Urtti (University of Helsinki, Finland). HCE cells were cultured in DMEM:F12 (1:1) without L-glutamine, supplemented with $15 \%$ fetal bovine serum and penicillin-streptomycin-L-glutamine $(100 \mathrm{U} / \mathrm{mL}, 100 \mu \mathrm{g} / \mathrm{mL}$, and $0.3 \mathrm{mg} / \mathrm{mL}$, respectively), and $5 \mu \mathrm{g} / \mathrm{mL}$ insulin (Invitrogen-Gibco). EGF (10 ng/mL; Invitrogen), 0.5\% DMSO (Riedel de Haën, Seelze Germany), and $0.1 \mu \mathrm{g} / \mathrm{mL}$ cholera toxin (Gentaur, Brussels, Belgium) were also added to the culture medium. The cells were maintained at $37^{\circ} \mathrm{C}$ with a $5 \% \mathrm{CO}_{2}$ humidified atmosphere. Cells of passages 38 to 40 were used in the experiments.

Mycoplasma-free IOBA-NHC cells were a gift from IOBA (Instituto de Oftalmobiología Aplicada, University of Valladolid, Spain). IOBANHC cells were grown in DMEM:F12 (1:1) without L-glutamine, supplemented with $10 \%$ fetal bovine serum, penicillin-streptomycin-Lglutamine ( $100 \mathrm{U} / \mathrm{mL}, 100 \mu \mathrm{g} / \mathrm{mL}$, and $0.3 \mathrm{mg} / \mathrm{mL}$, respectively) and 1 $\mu \mathrm{g} / \mathrm{mL}$ insulin (Invitrogen-Gibco). EGF ( $2 \mathrm{ng} / \mathrm{mL}$ Invitrogen), 0.2 $\mu \mathrm{g} / \mathrm{mL}$ cholera toxin (Gentaur), $0.5 \mu \mathrm{g} / \mathrm{mL}$ hydrocortisone, and amphotericin B (Sigma-Aldrich) were added to the culture medium. The cells were maintained at $37^{\circ} \mathrm{C}$ in a $5 \% \mathrm{CO}_{2}$ humidified atmosphere. Cells of passages 72 to 87 were used for the experiments.

\section{Analysis of CD44 Expression by Immunohistochemistry}

HCE cells were seeded at a density of $3 \times 10^{5}$ cells in coverslips. After 24 hours' incubation, the cells were washed with PBS and fixed with $2 \%$ paraformaldehyde in $0.1 \mathrm{M}$ phosphate buffer ( $\mathrm{pH} 7.4$ ). They were incubated with the blocking buffer ( $0.3 \%$ bovine serum albumin [BSA] and $0.3 \%$ Triton-X in PBS) for 10 minutes to block nonspecific binding and to permeabilize the cell walls. Hermes-1 antibody (obtained from DSHB [Developmental Studies Hybridoma Bank], Iowa City, IA, and developed by Eugene C. Butcher) was diluted 1:50 with 1\% BSA in PBS and incubated with the slides 2 hours at room temperature (RT). After five washes with PBS, the cells were incubated for 1 hour at RT with biotin-labeled anti-rat antibody (Anti-rat IgG; Sigma-Aldrich), diluted 1:100 in PBS. The cells were washed again with PBS and incubated with avidin-peroxidase ( $16 \mu \mathrm{L}$ in $1000 \mu \mathrm{L}$ PBS; ExtrAvidin; SigmaAldrich) for 30 minutes at RT. After washes with PBS, the cells were incubated in DAB-peroxidase substrate (Sigma Fast; Sigma-Aldrich) for 3 minutes at RT. After they were washed with distilled water, the cells were counterstained with Mayer's hematoxylin (Sigma-Aldrich) for 5 minutes at RT, washed with water, and mounted in mounting medium (Sigma-Aldrich). The specificity of the staining was controlled by incubating sections without the primary antibody. The slides were examined with a light microscope equipped with a digital camera (Eclipse TE 2000-S; Nikon Ltd., Kingston-upon-Thames, UK).

\section{Measurement of Cytotoxicity of NPs}

The cytotoxicity of the nanocarriers was studied in the HCE cells and IOBA-NHC cells. The cells were seeded at a density of $3 \times 10^{4}$ cells per well into 96-well culture plates (Costar, UK), 24 hours before the experiment. Increasing doses of the pDNA-loaded NPs (5-160 $\mu \mathrm{g}$ $\mathrm{NPs} / \mathrm{cm}^{2}$ cell culture) were incubated with the cells for 1 hour. After 
TABLE 1. Size and $\zeta$-Potential of pEGFP-Loaded Nanoparticles with $7 \%$ Loading

\begin{tabular}{|c|c|c|c|c|c|c|c|c|}
\hline \multirow[b]{2}{*}{$\begin{array}{c}\text { HA:CS } \\
\text { Mass Ratio }\end{array}$} & \multicolumn{2}{|c|}{ HA:CS } & \multicolumn{2}{|c|}{ HA:CSO } & \multicolumn{2}{|c|}{ HAO:CS } & \multicolumn{2}{|c|}{ HAO:CSO } \\
\hline & $\begin{array}{l}\text { Size } \\
(\mathbf{n m})\end{array}$ & $\underset{(\mathbf{m V})}{\zeta}$ & $\begin{array}{l}\text { Size } \\
(\mathbf{n m})\end{array}$ & $\underset{(\mathbf{m V})}{\zeta}$ & $\begin{array}{l}\text { Size } \\
(\mathbf{n m})\end{array}$ & $\underset{(\mathbf{m V})}{\zeta}$ & $\begin{array}{l}\text { Size } \\
(\mathbf{n m})\end{array}$ & $\underset{(\mathbf{m V})}{\zeta}$ \\
\hline $1: 2$ & $163 \pm 24$ & $+25 \pm 6$ & $115 \pm 13$ & $+20 \pm 4$ & $198 \pm 20$ & $+28 \pm 5$ & $103 \pm 7$ & $+23 \pm 10$ \\
\hline $1: 1$ & $160 \pm 16$ & $+18 \pm 3$ & A & A & $221 \pm 37$ & $+16 \pm 1$ & $173 \pm 53$ & $+10 \pm 6$ \\
\hline $2: 1$ & $191 \pm 16$ & $-30 \pm 8$ & A & A & $235 \pm 30$ & $+16 \pm 9$ & A & A \\
\hline
\end{tabular}

Data are the mean $\pm \mathrm{SD} ; n=3$. A, aggregation.

the NPs were removed, the cells were assayed for viability by using the MTS (3-(4,5-dimethylthiazol-2-yl)-5-(3-carboxymetoxyphenyl)-2-(4-sulfophenyl)-2H-tetrazolium) colorimetric assay (Promega Corp., Madison, WI).

\section{Transfection Studies in Proliferating Cells}

The capacity of the nanocarriers to transfect cells was evaluated in the HCE and IOBA-NHC cells. Twenty-four hours before the experiment, the cells were seeded at a density of $3 \times 10^{5}$ cells/well into 24-well culture plates (Costar). Naked pDNA and pDNA-loaded NPs were added to the cells in $300 \mu \mathrm{L}$ HBSS ( $1 \mu \mathrm{g}$ pDNA/well) and incubated for 5 hours. The cells were washed, and $1 \mathrm{~mL}$ of fresh culture medium was added to each well. The medium was changed the day after the transfection and every second day throughout the experiment. At different time points after transfection, GFP-positive transfected cells were detected by fluorescence microscopy (Eclipse TE 2000-S; Nikon Ltd.). Image-analysis software (Photoshop Elements; Adobe, San Jose, CA) was used to evaluate the GFP expression.

\section{Cellular Uptake Studies}

Sodium hyaluronate was labeled with fluoresceinamine (HA-fl), according to a modification of the method described by de Belder and Wik. ${ }^{27}$ In brief, $20 \mathrm{~mL}$ DMSO was added to $40 \mathrm{~mL}$ of $\mathrm{HA}$ in water $(1.25$ $\mathrm{mg} / \mathrm{mL})$. Subsequently, $0.5 \mathrm{~mL}$ of fluoresceinamine $(50 \mathrm{mg} / \mathrm{mL}$ in DMSO), in the presence of $25 \mu \mathrm{L}$ cyclohexyl isocyanide and $25 \mu \mathrm{L}$ acetaldehyde, were added to the HA solution. Magnetic stirring was maintained for 5 hours in darkness. The HA-fl was precipitated with a saturated solution of $\mathrm{NaCl}$ and ice-cold ethanol and then collected by centrifugation. Precipitate HA-fl was dissolved in ultrapure water and extensively dialyzed against distilled water for 24 hours, before lyophilization. The NPs were prepared according to the aforementioned methodology.

HCE and IOBA-NHC cells were seeded at a density of $3 \times 10^{5}$ cells per well, on sterile glass covers (Sigma-Aldrich) and placed in 24-well culture plates (Costar). Twenty-four hours later, $50 \mu \mathrm{L}$ of the NP suspension was incubated with the cells. After a 1-hour incubation, cells were rinsed with PBS and fixed (3.5\% paraformaldehyde/60 mM saccharose in PBS) for observation with the confocal microscope. The cell nuclei were counterstained with propidium iodide. Finally, the cell fluorescence was analyzed with a confocal laser scanning microscope (TCS SP2; Leica Microsystems, Wetzlar, Germany).

\section{Study of the Interaction of the NPs with the CD44 Receptor}

To determine whether the cell uptake of the NPs was receptor mediated, fluorescent NPs were added to the cells under different conditions. (1) The NPs were incubated with the cells at $37^{\circ} \mathrm{C}$ for 1 hour. Then, the cells were rinsed with PBS and fixed for observation with the confocal microscope. The cell nuclei were counterstained with propidium iodide. (2) The NPs were incubated with the cells at $4^{\circ} \mathrm{C}$ for 1 hour. Then, the cells were washed three times in acidic PBS, and the temperature was increased to $37^{\circ} \mathrm{C}$ for 20 minutes. Subsequently, the cells were rinsed with PBS and fixed, and the cell nuclei were counterstained. (3) The anti-human monoclonal antibody Hermes-1 (a monoclonal antibody that recognizes the N-terminal domain of CD44 and inhibits the HA binding) was added to the cells ( $1 \mu \mathrm{g} / \mathrm{well})$, and the cells were incubated at $4{ }^{\circ} \mathrm{C}$ for 20 minutes before the addition of the NPs. The solution was aspirated, and the cells were washed with PBS to remove the unbound antibody. Subsequent steps were performed as described in (2).

\section{Influence of the NP-CD44 Interaction in Gene Transfection}

The cells were transfected with $\mathrm{p} \beta$-gal-loaded NPs. The potential utilization of CD44 to aid in transporting pDNA into the cell nuclei was investigated by blocking the receptor with Hermes-1 and/or with an excess of HA/HAO (50-fold in relation to the HA content in the nanostructures), in which were the cells were incubated for $20 \mathrm{~min}$ utes at $4^{\circ} \mathrm{C}$. The antibody and the free polysaccharide were aspirated. Subsequently, the loaded NPs were added over the cells $(0.5 \mu \mathrm{g} / \mathrm{well})$, and incubated for 5 hours at $37^{\circ} \mathrm{C}$. The solutions of the NPs were

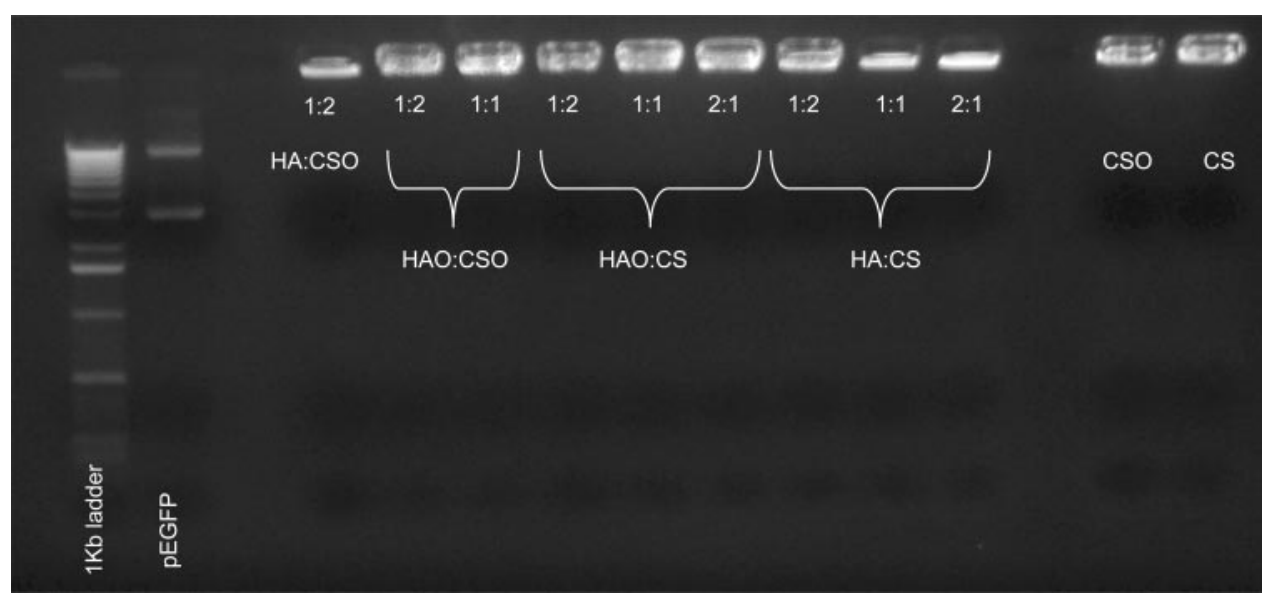

FiguRE 1. Gel retardation assay of the pEGFP-loaded NPs ( $7 \%$ theoretical loading) consisting on HA:CS of different molecular masses and increasing amounts of HA. As controls, NPs composed solely by CS or CSO were placed on the gel. 


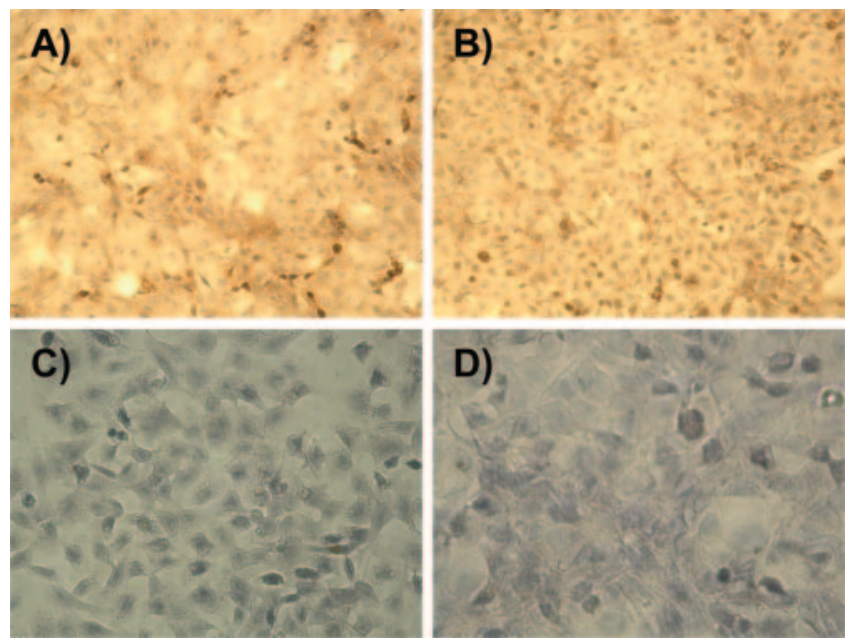

FiguRE 2. Light microscopy images showing the expression of CD44 receptor (brown) in (A) HCE cells visualized after immunostaining with anti-human CD44 antibody Hermes-1 and (B) IOBA-NHC cells visualized after immunostaining with anti-human CD44 antibody Hermes-1. The negative controls were performed by using the same protocol but without incubation of the primary CD44 antibody Hermes-1 in the (C) HCE cells and (D) IOBA-NHC cells. Magnification: $(\mathbf{A}, \mathbf{B}) \times 10 ;(\mathbf{C}, \mathbf{D}) \times 20$.

aspirated and replaced with fresh culture medium. Two days after transfection of the cells, the yield of the transfection was quantified. For the assay of $\beta$-galactosidase reporter gene expression, PBS was added to each well for washing, and then removed. Triton-X (2\%) in PBS was added to each well $(50 \mu \mathrm{L})$, and the cell lysates were obtained after incubation at $-80^{\circ} \mathrm{C}$ for 15 minutes. Fifty microliters of $0.5 \%$ FBS in PBS were added to each well, and finally, $150 \mu \mathrm{L}$ ONPG solution (2 $\mathrm{mg} / \mathrm{mL}$ in $60 \mathrm{mM} \mathrm{Na}_{2} \mathrm{HPO}_{4}$ buffer [pH 8] containing $1 \mathrm{mM} \mathrm{MgSO}_{4}, 10$ $\mathrm{mM} \mathrm{KCl}$, and $50 \mathrm{mM} \beta$-mercaptoethanol) was added. A standard curve was made using known concentrations of $\beta$-galactosidase, and the amount of expressed protein was estimated by a comparison to the standards. The plate was eventually assayed, and the absorbance of each well was measured at $405 \mathrm{~nm}$.

\section{Statistical Analysis}

The statistical significance was determined by the two-way ANOVA, and the $t$-test (SigmaStat Program, ver. 2.0; SPSS, Chicago, IL). Differences were considered to be significant at $P<0.05$.

\section{Results and Discussion}

\section{NP Formation and Characterization}

We report the preparation of nanosystems containing different proportions of $\mathrm{HA}$, as well as the influence of the molecular weight of both polysaccharides, HA and CS, on the in vitro behavior of the resulting NPs. The NPs were obtained by a very mild ionotropic gelification technique, initially applied to the preparation of CS NPs. ${ }^{25}$ The mechanism of formation of the nanosystems combines the electrostatic interaction between both polysaccharides, which are oppositely charged, with the ability of CS to undergo a liquid-gel transition because of its ionic interaction with TPP. In addition, both polysaccharides were expected to interact through hydrogen bonds and other intermolecular forces. ${ }^{26}$ On the other hand, pDNA was efficiently entrapped because of the strong interaction between its phosphate groups with the amino groups of CS, in addition to hydrophobic and hydrogen bonds between CS and the nucleotides. $^{21}$
Based on the hypothesis that the presence of HA in the NPs is critical for their utility in ocular gene delivery, we have prepared NPs with HA:CS mass ratios from 1:2 to 2:1. Moreover, for the preparation of these NPs we have used not only the commercially available polysaccharides (HA $160 \mathrm{kDa}$ and CS $125 \mathrm{kDa}$ ) but also oligomers obtained by partial depolymerization of the originals ( $\mathrm{HAO}<10 \mathrm{kDa}$ and CSO $10-12 \mathrm{kDa}$ ). In contrast, we have studied the influence of the amount of pDNA in the NPs formation process and observed that NPs could be obtained with a theoretical loading as high as $7 \%(7 \mathrm{mg}$ of plasmid DNA/100 mg of polysaccharides).

As shown in Table 1 , the size and $\zeta$-potential of the nanocarriers were dependent on the composition. In general, the reduction in CS molecular weight is accompanied by a decrease in the size of the NPs. The same observation was made for NPs composed solely by CS (CS NPs: $223 \pm 18 \mathrm{~nm}$; CSO NPs: $151 \pm 10 \mathrm{~nm}$ ).

It should be noted that there was a slight increase in size and a decrease in the surface charge due to the function of the HA content. More specifically, the NPs containing the highest amount of HA (HA:CS 2:1) underwent an inversion in their $\zeta$-potential, from positive to negative, thus indicating the disposition of the HA on the NP surface. This charge inversion was not observed in the case of HAO:CS 2:1 NPs, probably because of the different location of the HAO in the NP structure.

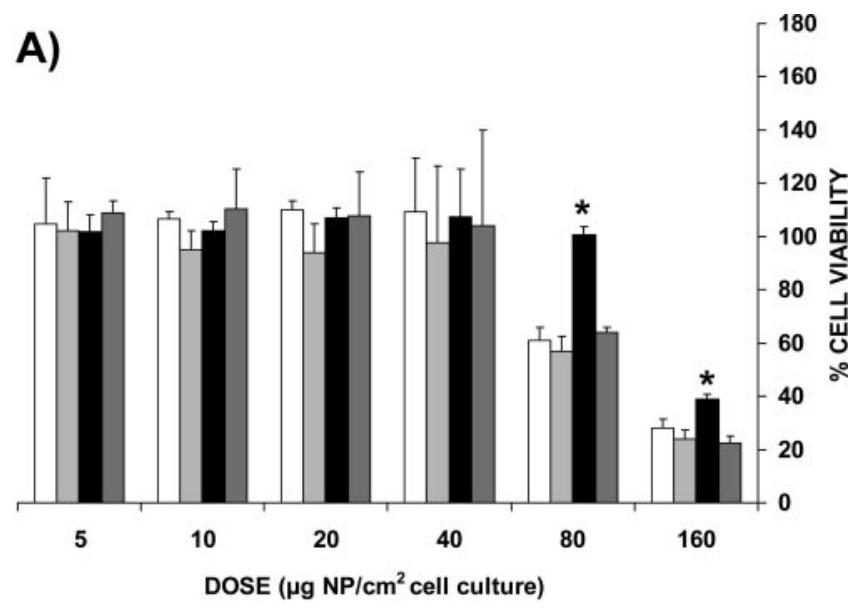

$\square \mathrm{HA}: \mathrm{CS} \square \mathrm{HA}: \mathrm{CSO} \square \mathrm{HAO}: \mathrm{CS} \square \mathrm{HAO}$ CSO

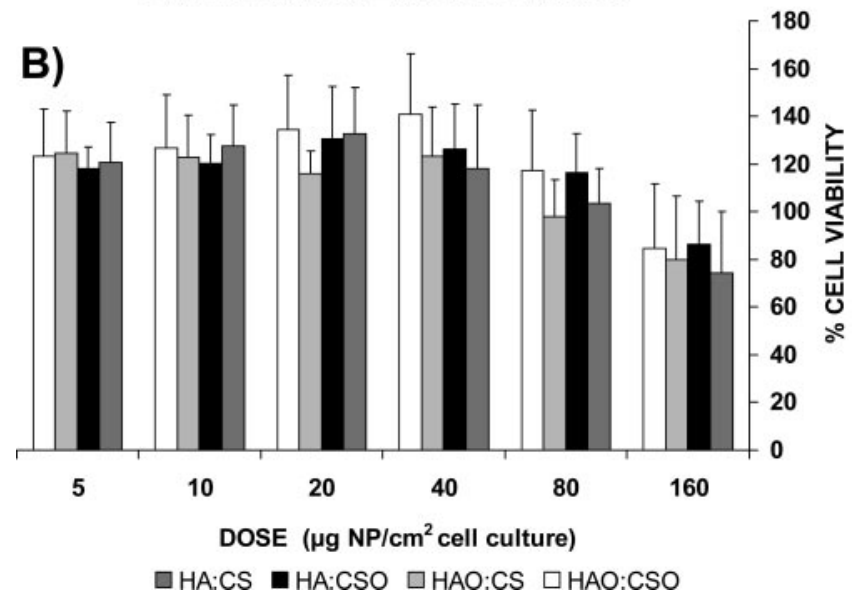

FIGURE 3. Cell viability on exposure to increasing doses of $7 \%$ pEGFPloaded NPs (HA:CS mass ratio 1:2). Comparison of HA:CS, HA:CSO, HAO:CS, and HAO:CSO NPs. The NPs were incubated for 1 hour with (A) HCE and (B) IOBA-NHC cells, and an MTS assay was subsequently performed (mean $\pm \mathrm{SD}, n=3$ ). *Significant differences, $P<0.05$. 

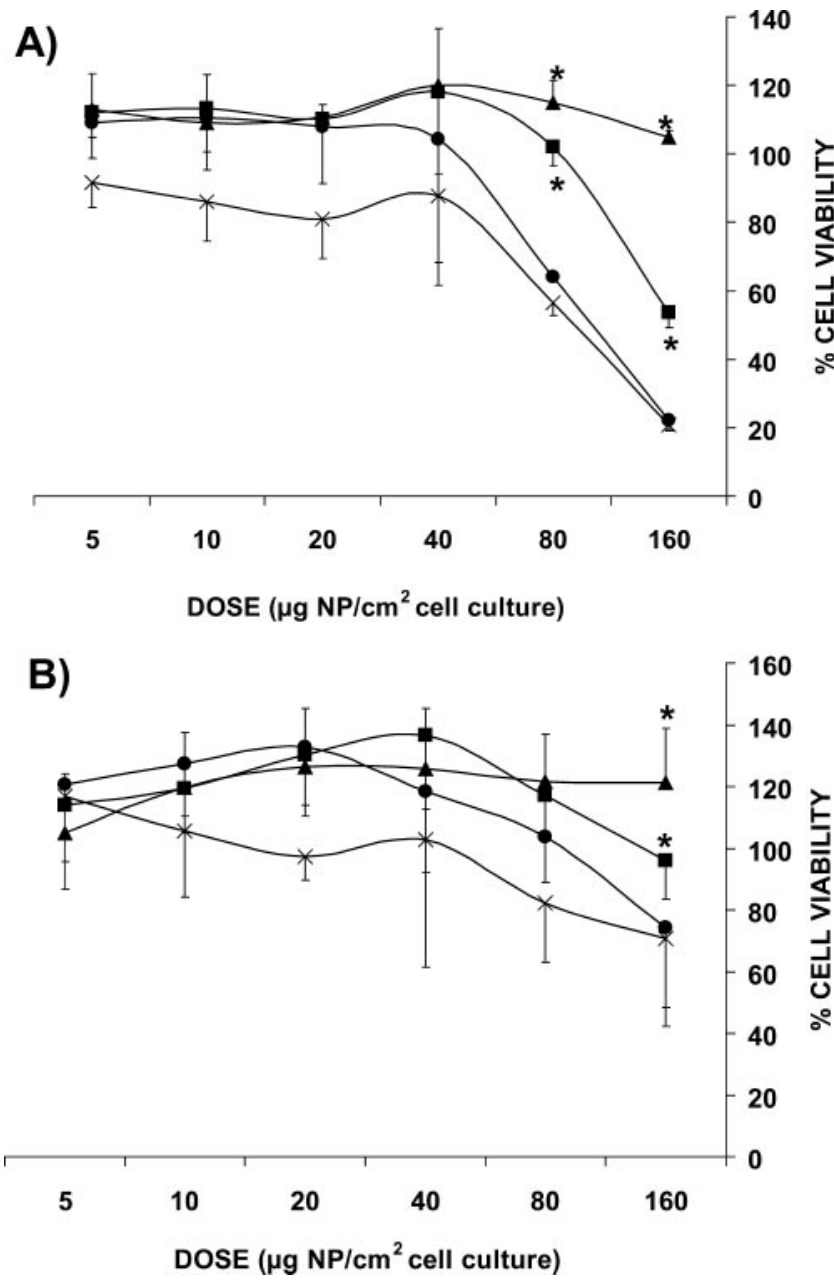

Figure 4. Levels of cell viability of (A) HCE and (B) IOBA-NHC cells, measured after a 1-hour incubation with $7 \%$ pEGFP-loaded NPs, composed of solely CS $(X)$ or CS in combination with increasing amounts of HA (HA:CS 1:2, 0 ; HA:CS 1:1. $\square$; and HA:CS 2:1. $\boldsymbol{\Delta}$ mean \pm SD, $n=3$ ). *Significant differences, $P<0.05$.

The ability of the polysaccharide NPs to entrap pDNA was studied by using an agarose gel electrophoresis technique. In general, the results observed for the NPs showed no migration of free pDNA in the gel, thus indicating that the pDNA was very efficiently associated with the NPs (Fig. 1). This result can be explained by the high affinity of the polysaccharide CS for the nucleotides. ${ }^{21-23}$

\section{Analysis of the CD44 Expression in Corneal and Conjunctival Cells by Immunohistochemistry}

As indicated in the introduction, one of the mechanisms whereby hyaluronan is thought to affect cellular events is via interaction with cell surface receptors, such as CD44. The ubiquitous plasma membrane CD44 receptor is known to be expressed in normal human and conjunctival cells ${ }^{13,14}$ and to contribute to hyaluronan internalization. ${ }^{15,16}$ Thus, given the expected critical role of the CD44 receptor in the internalization of NPs, in the present study, we used immunochemistry to examine the expression of this receptor in two model cell lines: HCE and IOBA-NHC. The results of the immunostaining with anti-human CD44 antibody Hermes-1 indicated that both HCE and IOBA-NHC cells had a high expression of the CD44 receptor in the study's experimental conditions (Fig. 2). Consequently, the selected cell lines can be considered to be good models for studying the internalization and DNA delivery capacity of HA-CS NPs.

\section{Study of the Cytotoxicity of HA-CS NPs}

A very important aspect of the development of new gene delivery carriers is the analysis of their toxicity on interaction with the target cells. In this study, we evaluated the cytotoxicity of HA-CS NPs in the HCE and IOBA-NHC cell lines by measuring their metabolic activity.

Figure 3 displays the percentage of cell viability as a function of the amount of NPs per square centimeter of cells. A first observation is that the cell viability values were dependent on the cell line. The NP compositions exhibited an obviously higher cytotoxicity in HCE (Fig. 3A) than in IOBA-NHC (Fig. 3B) cells. This behavior could simply be attributable to the different nature of the cells. Nevertheless, irrespective of this difference, the most important conclusion is that the highest $\mathrm{IC}_{50}$ (observed in the HCE cells) was between 80 and 160 $\mu \mathrm{g} / \mathrm{cm}^{2}-$ a value that greatly surpasses the particle concentration necessary for efficient cell transfection $\left(9.7 \mu \mathrm{g} / \mathrm{cm}^{2}\right)$.

An additional observation from Figure 3 is that the toxicity profiles of the nanosystems are very similar, independent of the molecular weight of the polysaccharides. Only significant differences were noted at the highest doses tested ( 80 and 160 $\mu \mathrm{g} / \mathrm{cm}^{2}$ ) for the NPs composed by HA:CSO (1:2), which rendered higher values on the levels of cell viability on incubation in HCE (Fig. 3A).
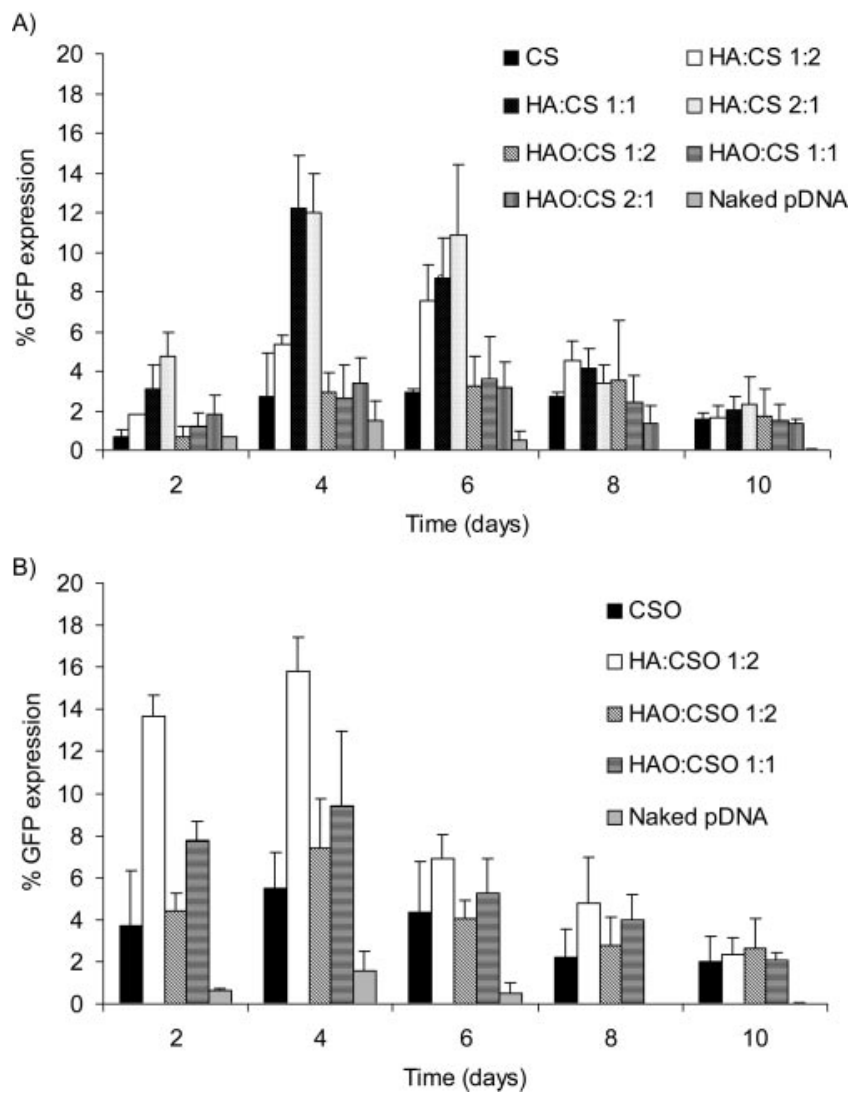

Figure 5. Evaluation of the transfection efficiency of HA-CS NPs in HCE cells. Percentage of transfected cells over 10 days after incubation of NPs composed of variable HA:CS ratios and different HA molecular weight (A). NPs composed solely of CS, HA:CS 1:2, HA:CS 1:1, HA:CS 2:1, HAO:CS 1:2, HAO:CS 1:1, or HAO:CS 2:1 NPs or of naked pDNA. (B) NPs composed solely of CSO, HA:CSO 1:2, HAO:CSO 1:2, or HAO:CSO 1:1 NPs or of naked pDNA (mean $\pm \mathrm{SD}, n=3$ ). 


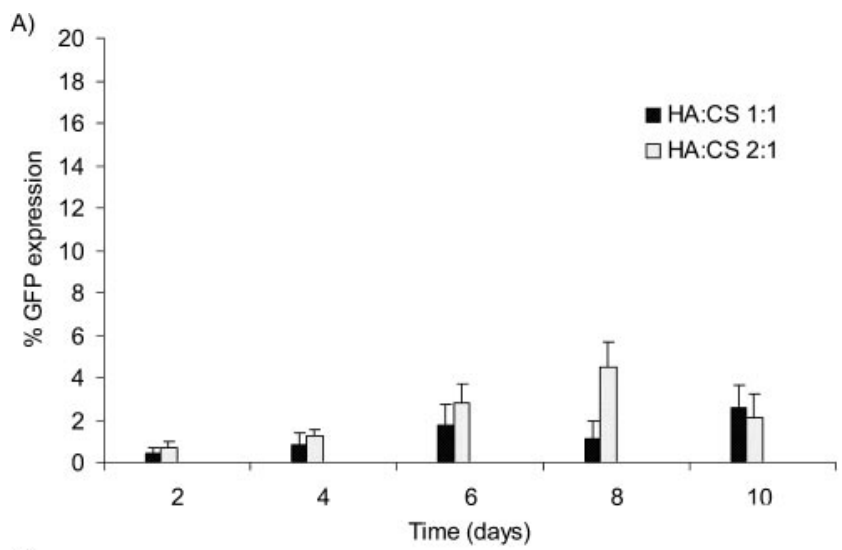

B)

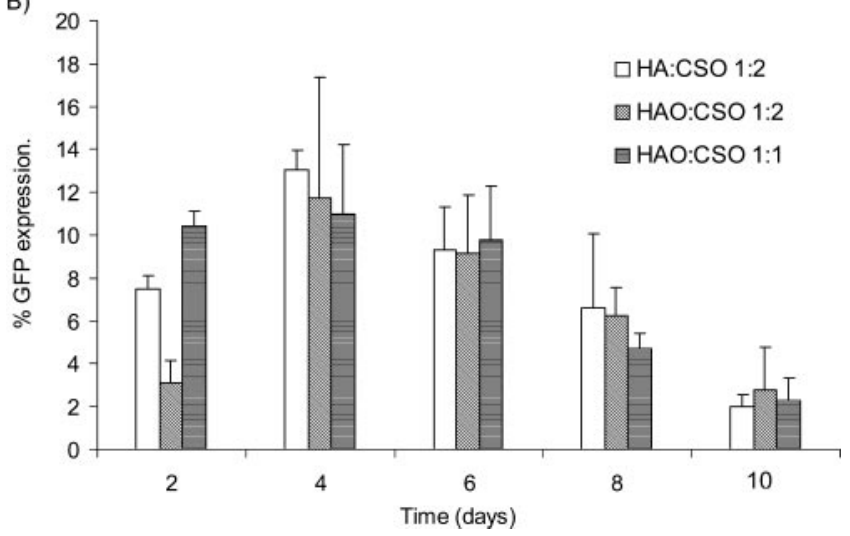

FIGURE 6. Evaluation of the transfection efficiency of HA-CS NPs in NHC cells. Percentage of transfected cells over 10 days after incubation of NPs composed of variable HA:CS ratios and different HA molecular weight. (A) NPs composed of HA:CS 1:1 and HA:CS 1:2. Undetectable levels of protein expression were found for CS; HA:CS 1:2; or HAO:CS 1:2, 1:1, and 2:1 NPs or naked pDNA. (B) NPs composed of HA:CSO 1:2, HAO:CSO 1:2, or HAO:CSO 1:1. Undetectable levels of protein expression were found with CSO NPs and naked pDNA (mean \pm SD, $n=3)$.

As a second step, with the idea of investigating the influence of the HA content of the NPs on their cytotoxicity, we incubated NPs composed solely of CS or CS in combination with increasing amounts of HA (NPs with a HA:CS mass ratios of $1: 2$., $1: 1$, and $2: 1$ ). We found that cellular toxicity depended on the HA content (Fig. 4).

As the amount of HA present in the NPs increased, a decrease in cellular toxicity was observed. In addition, the viability of the recovered cells was totally preserved on incubation of the HA:CS 2:1 NPs, irrespective of the dose. This positive feature could be explained by the high biocompatibility of the glycosaminoglycan hyaluronan and its implication in biological processes, such as the regulation of corneal epithelial regeneration, promotion of epithelial migration and wound healing, through an interaction with its receptor CD $44 .^{12}$

Overall, these findings indicate an adequate safety range for the application of these particles in ocular gene delivery.

\section{Transfection Efficiency of pDNA-Loaded NPs in Proliferating Ocular Cell Lines}

In the present work, we studied the capacity of the nanosystems to transfect two cell lines derived from the human corneal and conjunctival epithelia (HCE and IOBA-NHC). For this purpose, we used a green fluorescent protein-encoding plasmid (pEGFP) as a reporter gene. The GFP expression was observed for up to 10 days under a fluorescence microscope.
Figure 5 shows the levels of expressed green protein obtained after incubation of the pEGFP-loaded NPs in the HCE cell model. The results show that the ability of the NPs to transfect cells was strongly influenced by their composition. An additional observation is that the level of GFP expression increased with the amount of HA included in the nanostructures. This enhancement of the transfection efficiency could be a result of the presence of HA in the NP composition. First, HA could be expected to improve the internalization of the NPs as a result of specific and nonspecific interactions with the cells. Second, it has been reported that on internalization, HA is included in nonlysosomal vesicular compartments and rapidly accumulated in the perinuclear region and cell nuclei. ${ }^{28-30}$ Hence, trafficking could be speculated for the NPs containing HA that undertake intracellular pathways that favor the gene expression. ${ }^{31}$ Third, HA has been described as a transcription activator, that is able to enhance the transfection efficiency of HA-coated PEI complexes. ${ }^{32}$ Consequently, the same type of mechanism could apply to the HA-CS NPs.

An additional observation from the data in Figure 5 is that NPs made of oligomeric HA give lower levels of expression than those made of polymeric HA. This decrease in gene transfection efficiency could be related to a different location of HAO or to a reduced degree of incorporation of HAO into the NPs. Of interest, an opposite effect of molecular mass was noted for CS. In particular, the formulations composed by CSO promoted higher levels of gene expression than those made of CS. More specifically, the levels of gene expression exhibited by HA:CSO 1:2 NPs (Fig 5B) were notably higher than those corresponding to the HA:CS 1:2 NPs (Fig 5A). This result agrees with those reported by Köping-Höggård et al., ${ }^{33}$ who related the higher early expression with a more rapid release of the plasmid DNA from the NPs composed by CSO. Consequently, when taken altogether these results suggest that the most promising nanocarrier is that composed of CSO and HA.

The results obtained after transfection of the IOBA-NHC cells with the pEGFP-loaded NPs are shown in Figure 6. Naked pDNA was placed as a control, and no expression of the protein was detected. Overall, the obtained results correlate well with those reported for the HCE cell line, especially with regard to the factors that affect the efficacy of the nanosystems. However, a critical difference can be noted in the levels of gene expression achieved in each case. In fact, the NPs composed of solely CS were not able to transfect IOBA-NHC cells effectively and rendered undetectable levels of gene expression. Only those NPs containing important amounts of HA (HA:CS 1:1 and 2:1) elicited significant transfection levels (Fig. 6A). Undetectable levels of gene expression were also found for the NPs composed solely by CSO. The formulation containing $\mathrm{CSO}$ and $\mathrm{HA}$ or HAO (Fig. 6B) rendered levels of transfection that were closer to the ones reported for HCE cells.

A possible explanation for the different gene expression intensity obtained with both ocular cell lines could be related to their different surface properties, which could affect the interaction and internalization of the nanosystems. A crucial distinction between both cell lines relies on the fact that IOBA-NHC cells express mucins on their surface. ${ }^{34}$ Mucin may make it more difficult for the NP to interact with membrane receptor of the cells, thus affecting their internalization. Nevertheless, more experiments would be necessary to verify this possibility.

\section{Study of the Cellular Uptake of NPs}

In an attempt to elucidate whether the differences reported in the levels of transfection efficiency of the HCE and IOBA-NHC cells could be related to the transcellular penetration of the carriers, we decided to investigate the internalization of fluo- 


\section{HCE cells}
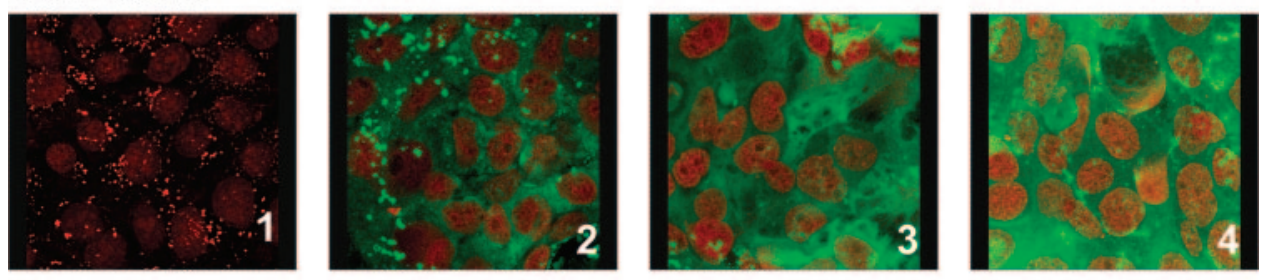

IOBA-NHC cells
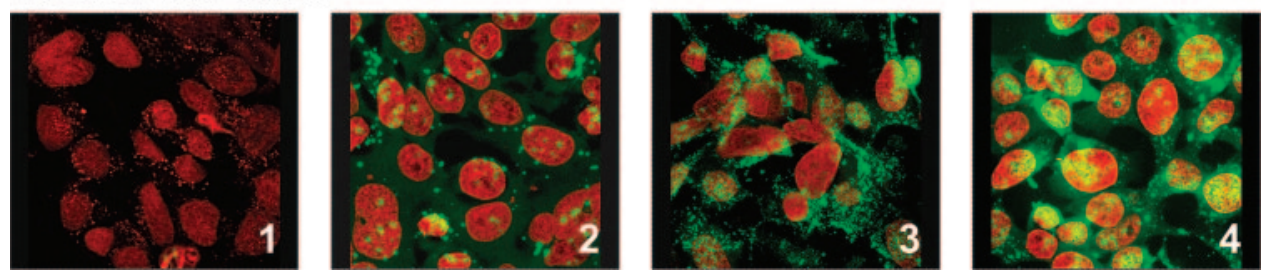

Figure 7. Confocal images showing the cellular uptake of (1) HA-fl solution, (2) HA:CSO mass ratio 1:2, (3) HA:CS mass ratio $1: 2$, or (4) HA:CS mass ratio 2:1 NPs after 1 hour of incubation with HCE or IOBANHC cells. The images are the projection of $\mathrm{x}-\mathrm{y}$ sections. HA was labeled with fluoresceinamine (green), and the cell nuclei stained with propidium iodide $(r e d)$. Magnification, $\times 63$.

rescence-labeled NP by using a confocal microscope. For this study, we selected the NPs composed of HA:CSO (1:2) given their optimal transfection results, and also the formulations consisting of HA:CS (1:2) and HA:CS (2:1). This last formulation has a negative $\zeta$-potential, probably due to the disposition of the HA on the NP surface and also gave reasonable high levels of gene expression in HCE and IOBA-NHC cells.

As noted by the localization of the intense green signal corresponding to the NPs, the images in Figure 7 indicate that, irrespective of their composition, the NPs are effectively internalized by the cells. An additional observation from these images is that, the ability of the NPs to enter the cells is more remarkable for HCE cells than for IOBA-NHC cells. These results, which are in good correlation with the transfection results, suggest that the internalization process is a limiting step for the efficiency of these nanocarriers as transfecting vehicles. Taking into account that a critical difference between both cell lines is the presence of mucin on the surface of IOBA-NHC cells, ${ }^{34}$ we could speculate about the possibility that the interaction of the nanosystems with the cell is somehow hampered by this additional barrier. From these results, we decided to conduct studies to elucidate further the mechanism of particle internalization by the cells in the HCE cell line. $37^{\circ} \mathrm{C}$

A)

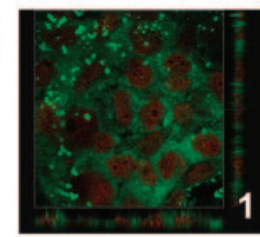

B)

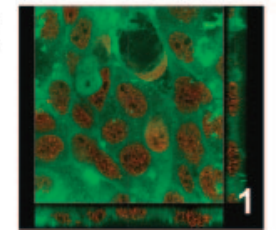

$4^{\circ} \mathrm{C}$
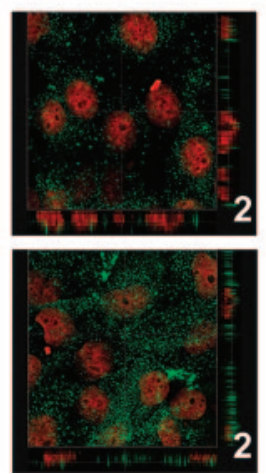

$4^{\circ} \mathrm{C}+\mathrm{Ab}$
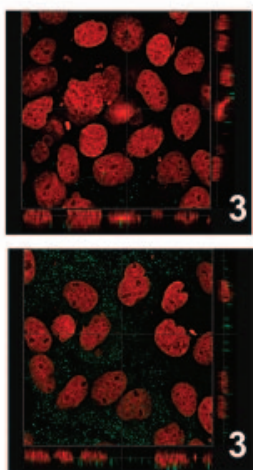

Figure 8. Confocal images showing the internalization of (A) HA: CSO (mass ratio, 1:2), and (B) HA:CS (mass ratio, 2:1) NP in HCE cells. The NPs were incubated at $37^{\circ} \mathrm{C}(1), 4^{\circ} \mathrm{C}(2)$, and $4^{\circ} \mathrm{C}$ after blocking of the CD44 receptor with the monoclonal antibody Hermes-1 (3). The images show cross sections in the $x-y$ and $x-z$ axes of the series. HA was labeled with fluoresceinamine (green), and the cell nuclei were stained with propidium iodide (red). Magnification, $\times 63$.

\section{Study of the Mechanism of Internalization of NPs: the Role of the CD44 Receptor in HCE Cells}

CD44 is the primary cell surface receptor for HA internalization and turnover. ${ }^{15,16}$ The HA binding to the cell surface is a complex interplay of multivalent events affected by the size of the HA ligand, the quantity and density of the cell surface receptor, and the activation state of $\mathrm{CD} 44 .{ }^{35}$ Based on this information, we expected that the presence of HA in the NPs would facilitate their access to the target cells and hence be critical to their success as gene carriers. In addition to this positive feature, it has been reported that the HA-CD 44 interaction leads to a cellular signaling process, ${ }^{12,36}$ which could promote the success of the gene transfection.

Particles with suitable sizes can enter mammalian cells by several routes (e.g., pinocytosis, phagocytosis, receptor-mediated uptake). In the particular case of NPs, the mechanism of internalization is thought to be an endocytic pathway. ${ }^{37,38}$ In the present work, we decided to evaluate whether HA:CS NPs could have access to cells through specific interaction with the transmembrane $\mathrm{HA}$ receptor, $\mathrm{CD} 44$. With this purpose in mind, we used fluoresceinamine-labeled NPs composed of HA: CSO (1:2; highest transfection efficiency) and compared them with those composed of HA:CS (2:1; higher HA content).

Taking into account that the HA-receptor binding proceeds at $4^{\circ} \mathrm{C}$ and $37^{\circ} \mathrm{C}$, whereas endocytosis occurs only at $37^{\circ} \mathrm{C}$, we

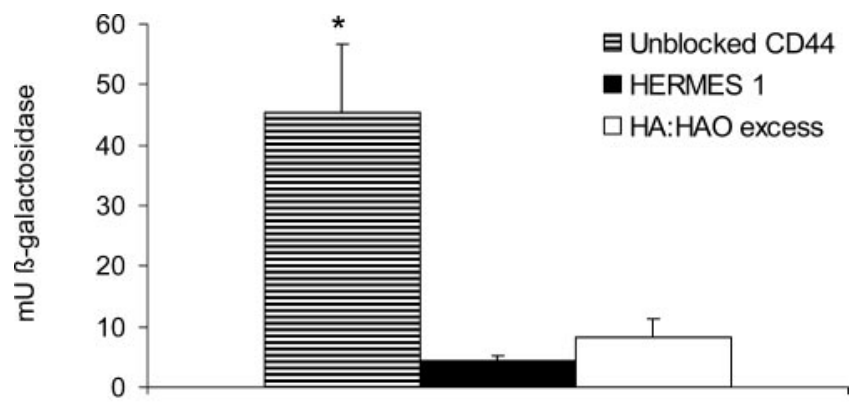

2 days post-transfection

FigURE 9. Evaluation of the transfection efficiency of pDNA-loaded NPs (HA:CSO 1:2) on incubation with HCE cells. The NPs were added over the cells. The CD44 receptor was blocked with $1 \mu \mathrm{g}$ of the monoclonal antibody Hermes- 1 or with an excess of a HA/HAO mixture (50-fold with respect to the amount of HA forming the nanostructures). The expressed $\beta$-galactosidase was quantified by the ONPG reaction. (mean $\pm \mathrm{SD}, n=3$ ). "Significant difference, $P<0.05$. 
decided to conduct the internalization studies in both conditions. As observed in Figure 8, NPs were extensively internalized at $37^{\circ} \mathrm{C}$, thus evidencing an endocytic mechanism of uptake. However, some cell association was also observed at $4^{\circ} \mathrm{C}$, a result that suggests a receptor-mediated uptake. Then, with the objective of elucidating whether CD44 is responsible for the receptor-mediated uptake, we blocked the receptor by the addition of the monoclonal antibody Hermes-1. The results showed that, as expected, the uptake of the NPs was almost negligible after the receptor blockage. Consequently, we concluded the internalization of HA:CS NPs may occur by CD44 receptor-mediated endocytosis.

Consequently, these findings suggest that both adsorptive and CD44 receptor-mediated endocytosis are involved in the mechanism of internalization of HA:CS NPs by the HCE cells.

Finally, after the observation of the capacity of the NPs to interact with the CD44 receptor, we thought it important to evaluate the influence of this interaction in the transfection efficiency of the $\mathrm{p} \beta$-gal-loaded HA:CSO 1:2 NP. For this purpose, we blocked the CD44 receptor by adding anti-CD 44 antibodies, or by excess of HA, before the addition of the plasmid DNA-loaded NPs. As shown in Figure 9, the levels of the expressed $\beta$-galactosidase were strongly diminished when the CD44 receptor was blocked. Therefore, we can conclude that the mechanism of transfection is partially governed by the interactions between the NPs and the HA receptor CD44.

\section{Conclusions}

In this report, we present a new type of NP consisting of HA and CS, which exhibit very low cytotoxicity, an ability to enter the corneal epithelial cells by CD44 receptor-mediated endocytic uptake, and the crucial capacity to deliver pDNA into both the corneal and the conjunctival cells, thus eliciting effective levels of protein expression. Therefore, these new NPs can be considered a promising means of ocular gene delivery.

\section{References}

1. Borrás T. Recent developments in ocular gene therapy. Exp Eye Res. 2003;76:643-652.

2. Patil SD, Rhodes DG, Burgess DJ. DNA-based therapeutics and DNA delivery systems: a comprehensive review. AAPS J. 2005; 7(1):61-77.

3. Lechardeur D, Verkman AS, Luckacs GL. Intracellular routing of plasmid DNA during non-viral gene transfer. Adv Drug Deliver Rev. 2005;57:755-767.

4. Fattal E, Bochot A. Ocular delivery of nucleic acids: antisense oligonucleotides, aptamers and siRNA. Adv Drug Deliver Rev. 2006;58:1203-1223.

5. Bloquel C, Bourges JL, Touchard E, et al. Non-viral ocular gene therapy: potential ocular therapeutic avenues. Adv Drug Deliver Rev. 2006;58:1224-1242.

6. Farjo R, Skaggs J, Quiambao AB, Cooper MJ, Naash MI. Efficient non-viral ocular gene transfer with compacted DNA nanoparticles. PLOS ONE. 2006;20(1:e38):1-8.

7. Peeters L, Sanders NN, Demeester J, De Smedt SC. Challenges in non-viral ocular gene transfer. Biochem Soc T. 2007;35:47-49.

8. Urtti A. Challenges and obstacles of ocular pharmacokinetics and drug delivery. Adv Drug Deliver Rev. 2006;58:1131-1135.

9. Klausner EA, Peer D, Chapman RL, Multack RF, Andurkar SV. Corneal gene therapy. J Control Release. 2007;123:107-133.

10. Lemarchand C, Gref R, Couvreur P. Polysaccharide-decorated nanoparticles. Eur J Pharm Biopharm. 2004;58:327-341.
11. Sánchez A, Alonso MJ. Nanoparticular carriers for ocular drug delivery. Nanoparticulates as Drug Carriers. London: Imperial College Press: VP Torchilin; 2006:649-673.

12. Aragona P. Hyaluronan in the treatment of ocular surface disorders. In: Garga HG, Hales CA. Chemistry and Biology of Hyaluronan. Oxford, UK: Elsevier, Ltd.; 2004:529-551.

13. Zhu SN, Nolle B, Duncker G. Expression of adhesion molecule CD44 on human corneas. Br J Ophthalmol. 1997;81(1):80-84.

14. Lerner LE; Schwartz DM, Hwang DG, Howes L, Stern R. Hyaluronan and CD44 in the human cornea and conjunctiva. Exp Eye Res. 1998;67:481- 484 .

15. Culty M, Nguyen HA, Underhill CB. The hyaluronan receptor (CD44) participates in the uptake and degradation of hyaluronan. J Cell Biol. 1992;116(4):1055-1062.

16. Knudson W, Chow G, Knudson CB. CD44-mediated uptake and degradation of hyaluronan. Matrix Biol. 2002;21:15-23.

17. Eliaz RE, Szoka FC Jr. Liposome-encapsulated doxorubicin targeted to CD44: a strategy to kill CD44-overexpressing tumor cells. Cancer Res. 2001;61(6):2592-2601.

18. De Campos AM, Sánchez A, Alonso MJ. Chitosan nanoparticles: a new vehicle for the improvement of the delivery of drugs to the ocular surface: application to cyclosporin A. Int J Pharm. 2001; 224:159-168.

19. De Campos AM, Diebold Y, Carvalho ELS, Sánchez A, Alonso MJ. Chitosan nanoparticles as new ocular drug delivery systems: in vitro stability, in vivo fate and cellular toxicity. Pharm Res. 2004; 21(5):803-810.

20. Diebold Y, Jarrín M, Sáez V, et al. Ocular drug delivery by liposome-chitosan nanoparticle complexes (LCS-NP). Biomaterials. 2007;28:1553-1564.

21. Mao H-Q, Roy K, Troung-Le VL, et al. Chitosan-DNA nanoparticles as gene carriers: synthesis, characterization and transfection efficiency. J Control Release. 2001;70:399-421.

22. Li WX, Lee DK, Chan ASC, Alpar HO. Sustained expression in mammalian cells with DNA complexed with chitosan nanoparticles. Biochim Biophys Acta. 2003;1630(1):7-18.

23. Mansouri S, Lavigne P, Corsi K, Benderdour M, Beaumont E, Fernandes JC. Chitosan-DNA nanoparticles as non-viral vectors in gene therapy: strategies to improve transfection efficacy. Eur J Pharm Biopharm. 2004;57:1-8.

24. Janes K, Alonso MJ. Depolymerized chitosan nanoparticles for protein delivery: preparation and characterization. J Appl Polym Sci. 2003;88:2769-2776.

25. Calvo P, Remuñán-López C, Vila-Jato JL, Alonso MJ. Novel hydrophilic chitosan-polyethylene oxide nanoparticles as protein carriers. J Appl Polym Sci. 1997;63:125-132.

26. De la Fuente M, Seijo B, Alonso MJ. Design of novel polysaccharidic nanostructures for gene delivery. Nanotechnology. 2008; 19(7):075105.

27. De Belder AN, Wik KO. Preparation and properties of fluoresceinlabelled hyaluronate. Carbohydr Res. 1975;44:251-257.

28. Collis L, Hall C, Lange L, Ziebell M, Prestwich R, Turkey EA. Rapid hyaluronan uptake is associated with enhanced motility: implications for an intracellular mode of action. FEBS Lett. 1998;440:444449.

29. Tammi R, Rilla K, Pienimäki J-P, et al. Hyaluronan enters keratinocytes by a novel endocytic route for catabolism. J Biol Chem. 2001;276(37):35111-35122.

30. Evanko SP, Wight TN. Intracellular localization of hyaluronan in proliferating cells. J Histochem Cytochem. 1999;47(10):13311341.

31. Ruponen M, Rönkko S, Honkakoski P, Pelkonen J, Tammi M, Urtti A. Extracellular glycosaminoglycans modify cellular trafficking of lipoplexes and polyplexes. J Biol Chem. 2001;276(36):3387533880.

32. Ito $\mathrm{T}$, Iida $\mathrm{N}$, Niidome $\mathrm{T}$, et al. Hyaluronic acid and its derivative as a multi-functional gene expression enhancer: protection from non-specific interactions, adhesion to targeted cells, and transcriptional activation. J Control Release. 2006;112(3):382388. 
33. Köping-Höggård M, Vårum KM, Issa M, et al. Improved chitosanmediated gene delivery based on easily dissociated chitosan polyplexes of highly defined chitosan oligomers. Gene Ther. 2004;11: 1441-1452.

34. Diebold Y, Calonge M, Enríquez de Salamanca A, et al. Characterization of a spontaneously immortalized cell line (IOBA-NHC) from normal human conjunctiva. Invest Ophthalmol Vis Sci. 2003;44: 4263-4274.

35. Entwistle J, Hall C, Turley EA. HA receptors: regulators of signalling to the cytoskeleton. J Cell Biol. 1996;61(4):569-577.
36. Toole BP. Hyaluronan in morphogenesis. Semin Cell Dev Biol. 2001;12:79-87.

37. Calvo P, Thomas C, Alonso MJ, Vila-Jato JL, Robinson JR. Study of the mechanism of interaction of poly( $\varepsilon$-caprolactone) nanocapsules with the cornea by confocal laser scanning microscopy. Int J Pharm. 1994;103:283-291.

38. Ma Z, Lim L-Y. Uptake of chitosan and associated insulin in caco-2 monolayers: a comparison between chitosan molecules and chitosan nanoparticles. Pharm Res. 2003;20(11):18121819. 